\title{
Feminismo, literatura e utopia: reflexões sobre uma "fotografia"
}

\section{ILDNEY CavalcantI}

Doutora em English Studies pela University of Strahçlyde, Escócia, atua como prótessora e pesquisadora no Programa de Pós-graduaçäo em Letras e Linguística (UFAL). É coordenadora do grupo de pesquisa Literatura e Utopia, winculado ao PPGLLUJFA, e do GT A Multher na Literatura, da ANPOLL.

Resumo: Este trabalho examina convergéncias entre os campos oiscursivos da teoria feminista, da literatura de autoria feminima e dos estudos da utopia. A partir dessa justaposiçāo. será discutida uma perspectiva de leitura utópico-leminista baseada no conceito de um "outro lugar" (an elsewhere) do discurso e da representaçāo, a partir de teorizaçōes de Julia Kristeva, Hélène Cixous, Luce Irigaray e Teresa de Laurelis. Propöe-se que o dualismo observado nas especulaçōes teóricas sobre o "outro lugar" seja abordado em seu caráter complementar: (a) como espaço de alteridade radical na escrita $\theta$ na representaçāo onde o desejo se inscreve, entendendo-o como motivador da propria escritura; ( situar-se dentro e fora das estruturas de poder existentes, permite perspectivas criticas e açōes transtormadoras. O entrecruzamento dessas posiçóes será iluminado a partir de um olhar sobre o poema "Fotografia", de Adelia Prado.

Palavas-chave: Feminismo. Literatura. Utopia.

Outro lugar (elsewhere) 

Without utopianism, feminism will grind to a halt. '

Lucy Sargisson, Contemporary feminist uropiansisn

\section{Feminismo, literatura e utopia}

Apesar de termos hoje em dia mil razóes para suspeitar de palavras como "esperança" e "utopia", há sinais que evidenciam a sobrevivência, e, aqui e ali, um renascimento de ideias utópicas. Esse renascimento pode ser observado concretamente na revisão radical, no âmbito de todas as esferas da experiência, proposta pelo movimento feminista. Um principio utópico, caracterizado pela crítica ao presente e pela projeção de um futuro alternativo, age como ponto central para o movimento. Assim, nāo parece acidental que o próprio termo "feminismo" tenha sido sugerido por um pensador reformista no contexto do socialismo urópico. ${ }^{2}$ Afinal de contas, o movimento traz consigo esperanças e desejos de práticas históricas alternativas ou, nas palavras do filósofo Ernst Bloch (1995), de um porvir histórico por cle denominado o "ainda-nāo".

De forma mais perceptivel, a partir do movimento feminista das décadas de 60 e 70 , observa-se, paralelamente ao feminismo manifestado arravés da militância política e da teoria e da crítica literárias, o surgimento de obras literárias de autoria feminina reveladoras de uma maior consciência do poder politico inerente ao ato de escrever. Essa consciência foi notadamente articulada pela poeta $e$ crítica norte-americana Adrienne Rich, que, numa frase que tem ressoado desde sua enunciaçāo no inicio dos anos 70 , colocou-se a favor de uma atitude revisionista $\mathrm{cm}$ relação à lireratura. Ela defende a "escritura enquanto revisão", definindo-a como "o ato de olhar para o passado, de ver com olhar renovado, de penetrar num velho texto a partir de um novo direcionamento crítico", num esforço para criar algo novo e como um "ato de sobrevivência" (1971, p. 167). ${ }^{3}$ Nessa passagem. é evidenciada sua preocupação com a tradiçāo e o cânone, um aspecto fortementc salientado neste ensaio: "Precisamos conhecer a escritura do passado, e conhecê-la de forma diferente
1 "Sem o utopismo o feminismo desgastar se-á até travar" (SARGISSON, 1996). Todas as traduçōes do inglès são minhas.

1 O termo, do qual o primeiro registro data da decada de 1890 , tem sua origem no francès féminisme, criado pelo socialista utopico Charles Fourier (1772 1837). Cf. Honderich. ed. 1995 . . 270.

3 "When we dead aw'aken: writing as revision", in Rich 1993. p. $166-177$. 
4 Do trabalho arqueológico da crftica feminista resulta o enfoque no pioneirismo em termos da questāo do gènero, no àmbito do subgénero da utopia literária, de La Cité des Dames (1405), de Christine de Pizan, que tern sido de modo geral regligenciado tanto pela crítica literária, quanto pelos compéndios históricos sobre uropismo literário, ambos de caráter mais tradicional. de como a temos conhecido: nāo para perpetuarmos uma tradição, mas para quebrarmos seu controle sobre nós" (167-168). Apesar de esse argumento descrever uma contradiçăo crucial e nāo resolvida da literatura e crítica feministas, ele ainda retém sua força original, que parece estar contida exatamente na tensảo que a sustenta.

O projeto de Rich sintetiza a dimensão utópica de uma escritura feminista, ao propor a desconstrução de um corpus literário tradicional hegemônico c historicamente flexionado no masculino, através da codificação do novo na reescritura. Nele estāo presentes os elementos fundamentadores do direcionamento utópico: crítica e projeçāo. A revisāo feminista do cănone abarcou e abarca vários gêneros literários, e isto inclui as utopias canônicas, dentreasquais a República (c. 370a.C.), de Platão, ea Utopia (1516), de Thomas More, são geralmente citadas como as obras representativas. ${ }^{A}$ Herland (1915), de Charlotte Perkins Gilman, ilustra a revisāo feminista do subgênero em sua forma eutópica, com a descrição de um "bom lugar" separatista para as mulheres. Esse texto oferece uma crítica não apenas à sociedade patriarcal contemporânea, como também expōe a pseudouniversalidade das utopias literárias publicadas anteriormente. Já as distopias feministas, mais visiveis na cultura a partir dos anos 60 , também apresentam uma escritura profundamente crítica e revisionista, porém, de forma duplamente perceptivel. Primeiramente, porque elas reescrevem uma tradição literária de autoria masculina, conforme se pode ilustrar através da obra de Monique Wittig, Across the Acheron (1985), que constrói uma crítica a vários mitos do paraíso e do inferno, tendo último sua representaçāo centrada na opressão de gênero na obra de Wittig, fator que inscreve o seu feminismo. Em segundo lugar, saliente-se o fato de as distopias efetuarem um outro tipo de escrita revisionista, no sentido de que elas emergem em nossa cultura também em resposta às eutopias licerárias ( $e$, no contexto da denominada crise da modernidade, que questionou as bases do próprio pensamento utópico). Desse modo, além de criticarem a sociedade contemporânea c revisarem 
uma tradição literária centrada na produçāo de autoria masculina, as distopias feministas também problematizam versōes anteriores (e mais ingênuas) do "bom lugar" flexionadas no feminino, como a de Gilman.

Não é apenas através das estratégias formais associadas aos subgêneros literários da eutopia e da distopia que se pode observar uma disposição utópica na literatura. Sendo maior do que a dimensão formal, a tendência ou qualidade utópica de um texto literário (bem como de outras manifestaçōes culturais) pode ser apreendida também em termos de funções e conteúdos, conforme nos lembra Levitas (1990). Essa ideia será reforçada com o comentário a seguir sobre entrelaçamentos entre crítica literária feminista e utopia, e com o olhar que será dirccionado sobre o poema "Fotografia", de Adélia Prado, discutido na última parte.

\section{Critica literária feminista e utopia}

Tratarei agora das atividades de ler e interpretar obras literárias partindo de uma perspectiva caracterizada como crítica e informada pelo feminismo. Uma breve discussāo sobre questōes concernentes ao feminismo e à critica literária feminista ajudará a esclarecer as relações entre essa vertente crítica c a noção de utopia, buscando explicitar uma possivel abordagem utópico-feminista. Feninismo tornou-se um termo vago por incorporar, em seus sentidos, uma diversidade de tendências e formas de açāo e abordagem. Apesar de essa diversidade apresentar, às vezes, visōes contraditórias e conflituosas, o que se tornou bastante visivel com o surgimento das muitas vozes conclamando diferenças nos feminismos dos anos 80 e 90 , a comunidade acadêmica feminista compartilha algumas premissas fundamentais. Um desses pontos de convergência reside na preocupação política com o âmbito social, um caráter pragmático (porém nāo programático) que caracteriza o movimento.

Nos estudos literários feminisras, obras pioneiras como U/n Teto Todo Seu (1929), de Virginja Woolf, e $O$ Segundo Sevo (1949), de Simone de Beauvoir - marcos 
de investigação pelo pioneirismo e escopo no âmbito do pensamento feminista do século $\mathrm{XX}$-, nunca perdem de vista as relações entre práticas textuais e sociais. E, apesar do desenvolvimento, da sofisticaçãoe das mudanças observadas na trajetória da crítica feminista literária e culcural desde a publicaçāo das análises iniciais empreendidas por Woolf e Beauvoir, seu foco centra-se ainda nas intersecçóes entre correntes sexuais, textuais e políticas, conforme tāo bern colocado por Robyn Warhol e Diane Herndl, na introdução a uma coletânea de textos críticos:

As/oscríticas/os feministas geralmente concordam que a opressão das mulheres é um fato da vida. que o gênero deixa traços nos textos licerários e na história literária, e que a crítica literária feminista excrce papel importante na luta para eliminar a opressāo no mundo fora dos textos. (1991, p. x)

Esse aspecto foi reforçado por Gerardine Meaney, que aponta ser exatamente tal propósito político comum o combustivel da proposta acadêmica feminista:

A natureza [dos] elos que unem [a produção acadêmica] com o ativismo feminista enriquecem a crítica feminista com uma vitalidade que proporciona à critica c aos estudos de gênero o único tipo de coesăo aceitável. Subjacente à diversidade intelectual há um propósito político comum, apesar de nāo único. A comunidade acadêmica feminista nào é alcançada sob o signo da renúncia à diferença, mas através da ativaçāo dessa diferença em energia política e intelectual. (1993, p. 2)

Essa conexāo com o que denominamos "mundo real", caracteristica das teorias feminisias, provocou un novo impulso nos estudos literários. $O$ trecho citado exemplifica bem tal aspecto, por meio da escolha dos termos "vitalidade" e "energia". 
Isso corna evidentes as relações entre as formas feministas de abordar textos culturais e a noção de utopia. Usando as palavras de Toril Moi, para citar mais uma crítica literária que reitera e sintetiza a linha de pensamento que está sendo traçada, "el principio de la crítica feminista há sido siempre político: tratar de exponer las practicas machistas para erradicarlas" (1995). Crítica à história e projeção de um espaço social melhor sāo o material da utopia, conforme já salientado. A crítica feminista sonha entâo com uma história calcada numa outra prática entre os sexos (que nāo a de hegemonia e opressāo que testemunhamos). Age em nome disso.

\section{Uma possibilidade de leitura utópico- feminista}

Prosseguirei essa discussão com uma proposta de ampliação ao que foi exposto acima, através da construção de uma forma de leitura que, orientada pela categoria de gênero e partindo de um plano conceitual teóricofeminista, observe criticamente a representaçăo literária do nosso lugar na história e, ao mesmo tempo, abra espaço para a utopia.

O conceito de um "outro lugar" (an elsewhere) do discurso e da representação consiste em um dos modos pelos quais um espaço utópico-feminista foi teorizado. Particularmente títil para o nosso propósito, esse espaço conceitual remete a significados diferentes para diferentes pensadoras. No trabalho de Julia Kristeva $(1974)_{r}{ }^{5}$ o "outro lugar" apresenta-se como um espaço no qual as mulheres năo se identificariam com a ordem simbólica (a lei do pai), nem seriam inspiradas por aquilo que essa ordem reprime, ato cuja consequência seria a vitimizaçāo. $O$ "outro lugar" para Kristeva seria um espaço no qual as mulheres poderiam identificar-se com o que foi reprimido pelo contrato simbólico, porém sem que figurassem como vítimas. Tal posição é desejável, mas nāo está disponivel historicamente, apesar de poder ser percebida através dos irrompimentos semióticos inscritos na linguagem poética. O maior obstáculo implícito nessa teorizaçāo da noção
5 "About Chinese Women" In: The Fristera Reader, Toril Moi, ed. 1986 , p. 139 158. 
6 Essa critica tem sido feita repetidamente por leitoras de Kristeva, Ver, por exemplo, a "Introduction", de Toril Moi. In: The Kristeva Reader (1986, p. 1-22), Felski 1989, Braidotti 1991.

7 In: Cixous e Clément The Newly Born Woman $(1996$, p. $63-$ 132). do "outro lugar" é que ela parece operar uma equaçāo entre as mulheres e um excesso semiótico (que se opōe a e ao mesmo tempo desestabiliza o contrato simbólico), arriscando assim aprisionar as mulheres exatamente no espaço que elaș têm historicamente ocupado. Outro perigo da equação entre o feminino e o "semiótico" (que, por sua vez, possui forte relaçāo com o inconsciente) reside na implicação, dela decorrente, de que a ordem simbólica da linguagem seja intrinsecamente opressora e hegemônica. ${ }^{6}$ De fato, na fusão entre o ser mulher e o nảo-lugar da linguagem, a teoria de Kristeva arrisca transformar esse ser feminino na própria utopia (em contraposição à visão deste ser enquanto sujeito histórico crítico e desejante da utopia). Contudo, esse "excesso semiótico" perceptivel na linguagern literária pode ser lido com vistas à operacionalização de uma função utópica, gerando então uma Ieitura positiva, ponto que será discutido adiante.

"Sorties" (1975), de Hélène Cixous, explora a ideia de um "outro lugar" enquanto espaço feminino que seja verdadeira e radicalmente "outro", em oposiçāo à alteridade histórica das mulheres ditada pela lógica do falocentrismo. Apesar de esse fio de pensamento apresentar uma contradição semelhante à comentada acima, o argumento de Cixous toca numa questão importante para a presente discussāo: a centralidade da escritura feminina no processo de busca do "outro lugar" utópico:

Deve haver algum outro lugar, digo a mim mesma. E todos sabem que para ir a algum outro lugar há rotas, sinais, "mapas" - para uma exploração. uma viagem. - Livros são isto. Todos saberr que um local exisre que não seja economicamente ou politicamente comprometido com toda a baixeza. Que não seja obrigado a reproduzir o sistema. A escritura é isto. Se há um outro lugar capaz de escapar à repetição infernal, enconträ-se naquela direçào, onde ela [a escritura] inscreve-se a si mesma, onde ela sonha, onde ela inventa nowos mundos. (1975, p. 72) 
Para Cixous, esse "outro hugar" existe na escritura enquanto espaço "onde o desejo faz a ficção existir" (1975, p. 97). Ela está se referindo à escritura feminina ( 'écricure féminine) em oposiçāo a uma tradiçāo literária falocêntrica que cai em repetiçāo narcisística. Ao mesmo tempo em que a ideia de uma alteridade histórica radical calcada numa cconomia 'verdadeiramente feminina' que escapa à codificação configura uma barreira intransponivel para os debates e teorias feministas (como tambèm o faz o conceito do "semiótico" proposto por Kristeva), Cixous expōe uma relaçāo entre o desejo por um "outro lugar" e a escritura, fator que oferece uma forma de se pensar o desejo utópico por um espaço de alteridade radical como consistindo precisamente naquele elemento que motiva a escritura ("faz a ficçāo existir").

Apesar das diferenças em suas elaboraçōes teóricas, as definiçōes do "outro lugar", de autoria de Cixous e Kristeva, podem ser lidas paralelamente pois, para as duas pensadoras, esse espaço utópico emerge na escritura: nos irrompimentos semióticos da linguagem poética e na escritura feminina. Observase outra convergência no sentido em que elas sugerem alteridades históricas radicais, estando, portanto, em sintonia com o conceito blochiano do porvir (o "aindanão"), ou aquilo que é totalmente novo e que pode ser vislumbrado em determinadas manifestaçóes culturais. Defendo que esse elemento pode, c deve, ser apropriado em leituras feministas.

A filósofa e crítica feminista Luce Irigaray fala de uma perspectiva diferenciada. Para ela, esse "outro lugar" configura-se enquanto espaço liminar, mais bem definido em termos de movimentos estratégicos do que de um posicionamento fixo: "um pé no sistema, outro fora", nas palavras de Rosi Braidotti (1991, p. 172). Tal posição dual, "travessia lúdica e desestabilizadora que permitiria à mulher a resdescoberta do lugar de sua "auto-estima"” (IRIGARAY 1977, p. 77), está implicita no jogo da mimese, compreendida por Irigaray enquanto re-encenação da condição, ou da existência, de mulher 
que se mostra "capaz de trazer novos elementos a essa construção" (1977, p. 76). Esse jogo pode promover o desmantelamento da ordem (fálica) vigente por ter a capacidade de "acrescentar uma perspectiva critica na nossa cultura em crise, bem como oferecer um ponto de partida para uma análise radicalmente nova dessa cultura" (BRAIDOTTI, 1991, p. 172). Diferentemente da noção do "outro lugar" do feminino à la Kristeva e Cixous, de acordo com Irigaray, tal espaço funciona a partir do interior mesmo das estruturas conceituais e sociais preexistentes, envolvendo um movimento simultâneo de repetição e desafio.

Outra pensadora feminista que investigou as possibilidades do conceito do "outro lugar" das (e para as) mulheres foi Teresa de Lauretis. Assim como Irigaray, sua visão desse espaço também é definida em relaçāo a um estado de liminaridade (implicando, portanto, um posicionamento duplo para uma subjetividade feminina) e perspectivada a partir de estruturas e instituições vigentes:

Penso [nesse "outro lugar"] enquanto espaços às margens dos discursos hegemônicos, enquánto espaços sociais escavados nos interstícios das instituições e nas fendas a rachaduras dos aparatos do poder/saber. E é ai que podem ser estabelecidos os termos de uma construção de gênero diferenciada - termos que agem efetivamente nos niveis da subjetividade e da auto-representação: nas práticas micro-políticas da vida diária e nas açōes de resistência do quotidiano que proporcionam tanto formas de agência quanto fontes de poder, ou investimentos que possam resultar en poder; e nas produçóes culturais de mulheres, feministas, que inscrevem aquele movimento para dentro e para fora da ideologia, aquela travessia de fronteiras - e dos limites - da(s) diferença(s) sexuais. (1987, p. 25. grifos meus) 
Percebe-se um forte sentido de imediação (e imediações) nas visōes de de Lauretis e de Irigaray. De acordo com essas pensadoras, o "outro lugar" é, de certa forma, oaquieagoradonossoambientesocialandrocêntrico e distópico. Elas falam sobre possiveis instâncias críticas, movimentos estratégicos, posicionamentos liminares. Pode-se afirmar que suas teorias são utópicas, no sentido em que buscam desmantelar estruturas falocêntricas (Irigaray) e reconstruir noções de gênero (de Lauretis). Apesar de teorizado nas décadas de 70 e 80 , o posicionamento contraditório proposto por ambas para o sujeito feminista tem tido impacto na teoria feminista mais recente (BRAIDOTTI, 1991; FUNCK, 1998).

Informada pelo que foi exposto acima, proponho a construçâao de uma hermenêutica utópico-feminista, baseada nessas duas noções do "outro lugar" do feminino que podem ser vistas como complementares: a. um espaço de alteridade radical na escrita e na representaçāo onde o desejo se inscreve, quer dizer, o "outro lugar" que motiva a própria escritura; e b. um espaço liminar que, ao situarse dentro e fora das estruturas existentes, permite às mulheres perspectivas críticas e açōes transformadoras. $\mathrm{Na}$ primeira orientaçāo, o horizonte utópico busca escapar de teorizaçōes; na segunda, abre caminhos para a formulação de noções de utopias como construçōes parciais, provisórias, processuais e ideológicas, aspectos cruciais para os debates contemporâneos sobre feminismo e utopia. Percebo essas orientaçòes enquanto tendências inextricavelmente ligadas, em constante complementaridade e fluxo, referindo-me a elas em separado por propósitos analíticos.

\section{0 "outro lugar" de uma "Fotografia"}

O poema "Fotografia", de Adélia Prado", em que um eu-lírico se debruça sobre a fotografia da mãe e compartilha suas impressōes com as/os leitoras/es, se nos apresenta, de forma mais imediata, enquanto uma construção dicotômica, polarizada entre a repetição de uma ordem dominante que segue a lógica de poder
- Em sua Poesia Reunida (1992). 
vigente e uma disposiçāo utópica subversiva dessa ordem e indicadora de uma alteridade histórica. Eis o texto:

\section{Fotografia}

Quando minha mãc posou

Para este que foi seu único retrato,

Mal consentiu em ter as têmporas curvas.

Contudo, há umin desejo de beleza no seu rosto

que uma doutrina dura fez contido.

A boca é conspicua,

mas as orelhas se mostram.

$O$ vestido é preto e fechado.

O temor de Deus circunda seu semblante.

como cadeja. Luminosa. Mas cadeia.

Seria um retrato triste

Se não visse em seus olhos um jardim.

Não daqui, Mas jardim.

Figuram, na descriçāo da fotografia, elementos sugestivos dos processos de apagamento e de repressāo historicamente impostos às mulheres. $O$ poema indica ter sido esse o "único retrato" feito, e que "uma doutrina dura" conteve a expressāo de "um desejo de beleza". O contexto em que a fotografia foi tirada demandava gravidade nas feições do rosto e na vestimenta ("a boca é conspicua", "o vest ido é preto e fechado"). E notável também, através de um viés marcadamente religioso, é o mecanismo de repressão manifestado pela símile contida nos versos 9 e 10: "o temor de Deus" que se impóe, "[circundando aquele] semblante como cadeia".

Estruturalmente construida por antiteses, evidenciase, na descrição da fotografia, a oposição das ideias entre a menção aos processos repressores acima descritos e a sutil sugestāo de um "outro lugar" do discurso e da representaçăo. sinalizado textualmente através do emprego das adversativas "contudo" e "mas", nos versos 4, 7 e 13. Essa construçāo reforça a tensāo dual entre o "zqui" histórico contextual dessa fotografia de mulher e o seu "outro lugar": 
uma doutrina dura

a boca conspicua

o temor de Deus/cadeia

o "aqui" do retrato um desejo de beleza

As orelhas [que] se mostram

a luminosidade

o jardim

Essa oposição também pode ser observada através do sofisticado uso da pontuaçāo no verso 10 , em que a "luminosidade" está contida entre pontos finais, que nos fazem lembrar as grades da "cadeia" através das quais a luz se derrama; bem como pela própria disposiçāo do poema na página, pois, enquanto uma margem reproduz a retidão da "moldura" mimetizando uma rigidez repressora, na outra, os versos apontam para fora dessa "moldura" feito setas."

Esse "outro lado" da foto, indicador de um espaço não disponivel naquele momento histórico para o sujeito fotografado, nào pode ser lido exatamente como equivalente aos irrompimentos semióticos inscritos na linguagem poética, conforme teorizou Kristeva, uma vez que esses últimos estariam manifestados textualmente através de quebras e rupturas no âmbito do verbal e da sintaxe, o que não chega a ocorrer no poema de Prado. Pode-se, porém, argumentar a favor de uma leitura desse "outro lugar" do poema, enquanto espaço de alteridade radical do feminino, ao observarmos a sutileza na escolha das imagens poéticas que nos fazem vislumbrá-lo sem que ele seja descrito. As referèncias a "um desejo de beleza" e a "um jardim não daqui", ambas de conteúdo fortemente utópico, uma vez que utopia pode ser definida enquanto expressão do desejo (LEVITAS, 1990) e tem sido imaginada na cultura ocidental através de jardins "famosos" (do Eden e das Delícias, por exemplo) condizem com um modo catacréstico de escritura, ao apontarem para o indizivel do linguagem, que é, paradoxalmente, expresso através da própria linguagem. Há, nesse silèncio paradoxal, a inscriçâo de uma dinânica texnal do desejo utópico, ${ }^{10}$ bem como um possivel alinhamento com o espaço do "semtótico" teorizado por Kristeva e com o "outro lugar" da escritura. onde. segundo Cixous, "o desejo faz a ficçāo existir." (Sendo

- Registro um agradecimento a Izabel Brandāo e a Cecilia Cunha que, presentes na sessāo de comunicaçöes em que estas reflexóes foram expostas, no $X$ Sentinário Nacional e I Seminhàio Internacional Mulher e Literarura (Joâo Pessoa, 2003). teceram os comentários relativos à pontuaçào do verso 10 e ao aspecto vistial do poema.

is Sobre a qualidade catacréstica da beleza em literatura, ver Barthes, 1970; e sobrc a centralidade dessa figura de linguagem na escritura utópica. Cavalcanti, 1999. 
o termo "ficção" aqui entendido de forma mais ampla, como sinônimo do fazer literário de modo geral.)

Uma outra forma de observarmos o "outro lugar" dessa fotografia resulta da consideração daquilo que excede a moldura do retrato, ou seja, da reflexão sobre a "moldura do poema" (em contraposiçāo à moldura da foto), que recorta o posicionamento do eu-lírico contemplando a imagem da mãe e compartilhando suas impressões com as/os leitoras/es. Evidencia-se aí a questão da recepção. Perspectivado a partir deste ângulo, o nosso olhar adquire a dimensão de un terceiro plano: olhamos um olhar (o do eu-lírico) que ol ha ainda um outro (o da imagem da mãe). O mise-en-abime quebra a dualidade apenas aparente advinda de uma primeira leitura do poema, sofisticando-o e problematizando-o.

A discussão a seguir, orientada pelo movimento de dentro para fora da fotografia, objetiva relacionar esse jogo poético em três dimensões e a segunda forma de teorizar o "outro lugar" enquanto espaço liminar que, ao situar-se dentro e fora das estruturas existentes, permite a construção de perspectivas críticas e açōes transformadoras em termos de relaçōes de gênero.

Já forarn expostas acima as formas pelas quais a descriçāo da imagem na fotografia é construida enquanto posicionamento dual, com "um pé no sistema, outro fora", nas palavras já citadas de Braidotti. Essa siruação pode ser percebida enquanto indicadora de uma siruação liminar e estratégica, que repete uma ordem hegemônica preexistente, subvertendo-a pela presença de um excesso nâo domesticado (e também inarticulado/ável).

Num segundo nivel, naquele em que é observado - local de enunciação do poema (ou seja, o local da fala do eu-lírico), enfatize-se que o poema apresenta uma crítica à nossa cultura, ao oferecer novos pontos partida para sua análise. Esse direcionamento é montado não apenas a partir do recorte diferenciado do objeto cultural examinado (a única foto da mãe), trazendo à superfície o que existia até então nas "fendas e rachaduras dos aparatos do poder/saber" - e que tão bem pode metaforizar a 
nossa açāo enquanto críricas literárias, traçando uma arqueologia do que havia sido negligenciado enquanto presença do feminino na cultura -, mas também pela apresentação de uma re-leitura do retrato em busca dos elementos utópicos, ou dos excessos, desafiadores da ordem que o produziu.

Orientando agora a leitura a partir do terceiro nível, aquele que abarca as relaçōes entre o texto do poema e suas/seus leitoras/es, faz-se interessante reler os últimos versos de um outro poema, "A arte de ser feliz", de Cecília Meireles, no qual figura um eu-lírico rememorando "as pequenas felicidades" encontradas em várias janelas vida afora:

quando falo dessas pequenas felicidades certas, que estāo diante de cada janela, uns dizem que essas coisas não existem, outros que só existem diante das minhas janelas, e outros, finalmente, que é preciso aprender a olhar, para poder vê-las assim, (Grifos meus.)

Esse texto nos fala do aprendizado do olhar, que é o ponto de convergência com o argumento que pretendo levantar: o de que um dos efcitos dos poemas de Meireles e de Prado, em nivel de recepção, é o de que, a partir da identificaçāo entre o eu-lírico e o/a leitor/a empírico/a, possa haver uma "educação do olhar", no sentido de se buscar, nos objetos da nossa cultura, aqueles elementos que apontam para os limites das ideologias e para os excedentes utópicos. Essa aproximaçāo entre o eu-lírico e o/a leitor/a resulta tanto da própria voz desse "eu", quanto da intimidade gerada pela estratégica escolha da poeta ao descrever uma situação em que o íntimo é compartilhado no ato de se perscrutar fotografias de família. Assim, tem-se uma dimensão de como pequenas práticas do quotidiano podem adquirir uma qualidade de ação micropolítica imediata, de ato de sobrevivência diante das nossas distopias. 


\section{Referências}

BARTHES, Roland. S/Z. Trans. Richard Miller. Londres: Jonathan Cape, 1970.

BLOCH, Ernst. The principle of hope. Trans. N. Plaice, S. Plaice \& P. Knight. Cambridge, Mass: MLT, 1995.

BRAIDOTII, Rosi. Patterns of dissonance: a study of women in contemporary philosophy. Trans. Elizabeth Guild. Cambridge: Polity, 1991.

CAVALCANTI, Ildney, A distopia feminista contemporánea: urn mito e uma figura. In Muzart. Zabidé (org.) Boletim do G'T A Mulher na Literatura. Vol. 9. Florianópolis: ANPOLL/ UFSC, 2002.

Articulating the elsewhere: utopia in contemporary feminist dystopias. Tese de Dothoramento. University of Strathclyde. Glasgow, Escócia, 1999.

CIXOUS, Hélène (1975) Sorties. In Cixous, Hélène \& Clément, Catherine The newly born woman. Trans. Betsy Wing. London: Tauris, 1996.

FELSKI, Rita. Beyond feminist acsthetics: feminist literature and social change. London: Hutchinson Radius, 1989.

FUNCK, Susana. Feminist literary utopias. Florianópolis: UFSC. 1998.

HONDERICH, Ted ed. The Oxford companion to philosophy. Oxford and New York: Oxford University Press, 1995.

IRIGARAY, Luce (1977) This sex which is not one. Trans. Catherine Porter. Ithaca, New York: Cornell U.P., 1996.

KRIST"EVA, Julia (1974). About chinese women. In Moi, Toril ed. The Kristeva reader. Oxford: Blackwell, 1986. 
DE LAURETIS, Teresa (1987). Technologies of gender; essays on theory, film and fiction. London: MacMillan, 1989.

LEVITAS, Ruth. The concept of utopia. Hempstead: Philip Allan, 1990.

MEANEY, Gerardine. (Un)Like subjects: women, theory, ficcion. London \& New York; Routledge, 1993.

MOI, Toril. Teoria literaria feminista, Madrid: Cátedra, 1995.

PRADO, Adélia. Poesia reunida. São Paulo: Siciliano, 1992.

RICH, Adrienne. Adrienne Rich's poetry and prose. Sel. and ed. Barbara and Albert Gelpi. New York and London: W.W. Norton and Co., Inc., 1993.

SARGISSON, Lucy, Contemporary feminist utopianism. London: Routledge, 1996.

WARHOL. Robyn \& D. P. HERNDL eds. Feminisms - An anthology of literary theory and criticism. New Brunswick, New Jersey: Rurgers University Press, 1991. 